\title{
Information System Backsourcing: A Systematic Literature Analysis
}

\author{
Christian Leyh \\ Technische Universität Dresden \\ Chair of Information Systems, esp. \\ IS in Manufacturing and \\ Commerce, Helmholtzstr. 10, \\ 01069 Dresden, Germany \\ Email: Christian.Leyh@tu- \\ dresden.de
}

\author{
Thomas Schäffer \\ University of Applied Sciences \\ Heilbronn, Faculty of Business \\ Administration, Max-Planck-Str. \\ 39, 74081 Heilbronn, Germany \\ Email: Thomas.Schaeffer@hs- \\ heilbronn.de
}

\author{
Trung Duc Nguyen \\ Technische Universität Dresden \\ Chair of Information Systems, esp. \\ IS in Manufacturing and \\ Commerce, Helmholtzstr. 10, \\ 01069 Dresden, Germany
}

\begin{abstract}
As information technology (IT) in private and public organizations continues to gain importance, information system outsourcing (ISO) has become a critical component of corporate strategy for many institutions. Consequently, a substantial amount of research has investigated topics around ISO decisions and outcomes. However, despite decades of ISO research, analyses that focus on information system (IS) backsourcing remain scarce. Therefore, in this paper, we share the results of a systematic literature analysis of papers that consider IS backsourcing. Within our paper, IS backsourcing is integrated into the wider research landscape of ISO. Finally, our study clearly identifies the need for further and more extensive research on IS backsourcing. The high dissatisfaction and failure of outsourcing arrangements should not be ignored. Both sourcing decisions and existing outsourcing arrangements must be analysed carefully and in the long term to ensure the success of the company.
\end{abstract}

\section{INTRODUCTION}

$\mathrm{I}$ nformation system outsourcing (ISO) has become a common alternative to running in-house information technology (IT) operations and development activities across company and national borders. Looking at the ever-growing range of IT services that are available in the global outsourcing market, companies can purchase not only small development and hosting services but also entire business process and infrastructure solutions. Thus, information system outsourcing (ISO) / information technology outsourcing (ITO) has become a well-established field of research. Typical research topics evolved from ISO motivations and success factors in the $1990 \mathrm{~s}$ to the relationship between vendor and client in the $2000 \mathrm{~s}$ to modern forms of sourcing in approximately 2008 [1].

ISO/ITO are backed by many drivers: optimized cost situation (mainly through high labour cost differences), access to highly qualified staff, access to new markets, high flexibility and technical feasibility. These factors weigh even more heavily if the company-owned IT department experiences a lack of competence, high costs or a lack of attention because it does not belong to the core business [2].

What seems like an ideal solution comes with a variety of

This work was not supported by any organization risks and problems. These range from global client risks, which include the state of the labour market and the infrastructure in the provider's country, to local client risks, such as cultural differences, different time zones, language problems, knowledge transfer and technical skills, which hamper the quality of the cooperation [3]. Further risk factors are, for example, interest conflicts, low product or service quality, high turnover rates on the provider-side, additional work and extra costs for the client and technologyrelated risks [4]. Referring to practice-oriented studies, many of the stated risks have become problems [5]. This argument is also supported by surveys that report that $50 \%$ of analysed offshore outsourcing contracts that are signed by North American companies failed to meet their expectations [5], 30 to $50 \%$ of the companies that are involved in offshore outsourcing had cancelled their contracts [6], and $20 \%$ of those outsourcing contracts are cancelled in the first year [7].

One of several alternatives for a company that is facing those problems is to terminate its relationship with the vendor and relocate its IT services. Therefore, this paper will focus on backsourcing as one type of relocation. IS backsourcing in the IS literature is generally defined as the process of recalling operations back in-house after they have been outsourced [8]. The practice of IS backsourcing has been only briefly discussed in the scientific literature, compared to the growing literature on ISO/ITO [9]-[11]. This is surprising when examining some of the numerous prominent cases, where banks such as JP Morgan Chase and Bank One prematurely terminated their multi-billion-dollar ITO contracts to pull those services back in-house [12]. Such cases highlight the practical relevance of IS backsourcing. To address the knowledge void that surrounds this phenomenon, it is necessary to analyse the state of the academic literature on IS backsourcing, to answer the most important question, namely, "Why backsource IT services?", and determine what is known about the transition process to answer the question "How can IT services be backsourced?".

Therefore, the main objective of our paper is to identify drivers for IS backsourcing and factors that influence the transition phase in the existing academic literature. To fulfil this objective, we conducted a systematic literature analysis. 
With this analysis, we aim at answering two research questions:

\section{- What are drivers for companies to backsource their IT services? \\ - How do companies backsource their IT services?}

To obtain an initial answer to these questions, the paper is structured as follows: First, we present a short overview of our methodology. Next, as the main focus of our paper, we describe in detail the findings of our literature analysis. Then, we conclude with a discussion and summary of our results and identify aspects for future research.

\section{RESEARCH APPROACH}

\section{A. Literature Review}

To obtain a general overview of the body of IS backsourcing research, we followed the guidelines of [13], in which a five-step approach for conducting IS literature reviews is provided. In the first step, we defined the review scope, backed by a taxonomy of literature reviews that were developed by [14]. In steps 2 and 3, relevant working definitions (for a common understanding of the used search terms) and the search process (sources and the selection criteria for the literature) are described. The definition of analysis and synthesis is assigned to the fourth step, including a categorization referring to [12], [15]. The final step is composed of summarization of key findings and specification of a research agenda.

As an initial step, we examined IS journals and IS conference proceedings using the databases AIS Electronic Library, EBSCOhost Business Source Complete, Emerald Insight, IEEE Xplore and ScienceDirect. We conducted electronic searches of titles, keywords and abstracts for the following search term: ["backsourc*" OR "backshor*" OR "reshor*" OR "insourc*”]. Furthermore, we performed a second search on the following search term: [("offshor*" OR "outsourc*") $A N D$ "fail*"]. With these searches, we identified 290 publications. After analysing each article's abstract and keywords, and/or the full article when necessary, we excluded 220 articles that were duplicates or did not appear to be concerned with or relevant to our research focus. As a third analysing step, by reading the abstracts of the remaining 70 papers, we selected only 15 papers for deeper review. In the last step, five additional publications were identified through backward and forward search (as suggested by [16]). Table 2 in the Appendix gives an overview of the 20 publications that elaborate a consolidated view of the current field of IS backsourcing. In the remainder of this article, we focus on these papers.

\section{B. Literature Analysis and Synthesis Framework}

For the analysis and synthesis of the relevant literature, the analytical framework of [4] is partially considered, which refers to the perspectives research focus and research approach.
Research Focus: Dibbern et al. [2] developed a five-stage model of ISO. These five stages are divided into two main phases: the decision process and the implementation. The decision process contains the following questions and stages: Stage Decision: (1) Why does an organization consider outsourcing? (e.g., drivers, antecedents), (2) What is outsourced? (e.g., functions, organizations) and (3) Which choices are made? (e.g., with a decision model or guideline); Stage Implementation: (4) How is outsourcing carried out? (e.g., selecting vendors, transition of knowledge) and (5) What are the outcomes of outsourcing? (e.g., experience, lessons learned). Since backsourcing is a major decision in an organization, the adoption of this stage model appears appropriate. Thereby, our paper focusses on the two main stages by reducing the decision process to the "WHY" stage and the implementation to the "HOW" stage. This limitation is backed not only by the foci of most of the IS backsourcing literature, which instead examines the antecedents of backsourcing, but also by the similarity of the transition process in outsourcing and backsourcing in terms of influencing factors (see [17]).

Research Approach: Referring to the view on research approaches of [2], the identified literature was analysed and we differentiated between empirical and non-empirical approaches. Thereafter, the epistemology within the approaches was determined by following [4]. Empirical approaches contain the following types of epistemology: interpretivism, positivism and descriptivism, whereas nonempirical approaches can be distinguished between conceptual and mathematical methods.

\section{FINDINGS}

As a result of the literature analysis and synthesis, this section outlines the determinants for backsourcing IT services and the factors that influence the transition phase. Working definitions are specified in the first part, followed by a descriptive analysis of the findings and their methodologies. Subsequently, the drivers and transition process influencers for IS backsourcing are analysed and synthesized.

\section{A. Conceptual Background}

Prior to identifying the drivers for outsourcing failure and relocating IT services from an offshore location to the home country, various working definitions must be clarified. As backsourcing is a type of general sourcing in the academic literature, both IS and manufacturing definitions could be applied. Especially in manufacturing literature, multiple synonyms are used, such as back-shoring, reshoring, backsourcing and de-internationalization (see [18]). In IS research, mainly the terms backsourcing and insourcing are being used. Table 1 presents an overview of existing definitions.

A comparative analysis of the definitions that are found in both the IS and manufacturing literature (see Table 1) 
reveals several characteristics of the relocation of manufacturing or IT services back to the home country of the company: (a) the relocation is the reverse decision with respect to a previous offshoring process, (b) the relocation does not necessarily involve repatriation or the closure of all of a company's offshore activities or plants and (c) a difference between the ownership modes can be identified (backshoring and backsourcing).

Referring to [4], in which a framework was specified for classifying the characteristics of the term offshoring, almost all characteristics can be assumed to be parallel to backsourcing. Only the category Distance may be left out, since the destination for the backshoring action is usually the domestic country of the company by definition. Thus, the focus lies on three characteristics (see [2], [4], [19]):

- Ownership (What property model shall be used?),

- Function (What IS services shall be backshored?) and

- Degree (To what extent shall IS services be backshored?).

These characteristics can be further divided into internal, external, partial, selective and total.

(1) Ownership: As opposed to offshoring, where the action begins in the home country of the company, backsourcing starts in the country to where the services have already been located. Hence, several reshoring alternatives are possible. Company internal IS services can generally be reshored to captive organizational units that are still located in foreign countries (in-house reshoring following [20]). They can also be reshored to partially owned companies (e.g., joint ventures or strategic alliances, following [10], [21]) or externally owned companies (near-/ offshore outsourcing, following [22]).

(2) Function: Strasser and Westner [23] determined that most studies do not specify which IS services are transferred, as often only general terms such as information system development activities and IS functions are stated. By clustering these terms, three groups of activities are defined: infrastructure services, application development services and business process services ([4], [21]).
(3) Degree: Here, distinctions between total and selective reshoring can be made ([21], [24], [25]). Contrary to the case of total offshoring, total reshoring of previously outsourced or offshored services is realistic.

This paper will focus on backsourcing as one case of relocating IS services. As the drivers for relocating IS services to the home country of a company will be investigated, backshoring, which is used primarily in the manufacturing reshoring literature, will be considered as well. This paper follows the initial definition of backsourcing of [26]: "[...] backsourcing, where companies who initially outsourced their IT decide to bring it back in-house." For the remainder of our review, further specifications were set to avoid ambiguities in the stated characteristics of reshoring: The backsourced IS services are considered to be integrated into the company-internal organization, which is located in the home country of the company. Only internal functions are backsourced entirely.

\section{B. Applied Research Methodologies}

The selected conference and journal publications regarding IS backsourcing can be divided into non-empirical (conceptual or mathematical) and empirical (interpretive, descriptive or positivist) papers. Mathematical modelling papers were not found. An overview on who used which approach can be found in Table 2 in the Appendix.

The non-empirical conceptual research papers include issues and perspectives that are related to the phenomenon of IS backshoring. Akoka and Comyn-Wattiau [27] designed a framework for understanding "Why to backsource IT" by defining rational and irrational factors. Another framework for understanding the decision to backsource IT was created by [28], who regarded the reasons for IT backsourcing not only as a problem-solving strategy but also as an internally or externally motivated opportunity for stability and growth. Another backsourcing decision model was constructed by [29], in which a decision process is designed by integrating knowledge from the research literature and expert interviews.

TABLE I.

OVERVIEW OF TYPES OF RESHORING

\begin{tabular}{|c|c|c|}
\hline Concept & Definition & References \\
\hline Backshoring & $\begin{array}{l}\text { "Re-concentration of parts of production from own foreign locations as well as from foreign } \\
\text { suppliers to the domestic production site of the company" [30] }\end{array}$ & {$[30]-[32]$} \\
\hline Backsourcing & $\begin{array}{l}\text { "[...] where companies who initially outsourced their IT decide to bring it back in-house." [26] } \\
\text { "Production return relocation from an }[\ldots] \text { external entity" }[31]\end{array}$ & {$[26],[31],[33]$} \\
\hline $\begin{array}{l}\text { De-internatio- } \\
\text { nalisation }\end{array}$ & $\begin{array}{l}\text { "Any voluntary or forced action that reduces a company's engagement in or exposure to } \\
\text { current cross border activities" [34] }\end{array}$ & {$[34]-[36]$} \\
\hline Insourcing & $\begin{array}{l}\text { "Insourcing is the practice of evaluating the outsourcing option, but confirming the continued } \\
\text { use of internal IT resources to achieve the same objectives of outsourcing" [11] }\end{array}$ & {$[11]$} \\
\hline Reshoring & "Moving manufacturing back to the country of its parent company" [37] & {$[20],[37]$} \\
\hline
\end{tabular}


Moreover, McLaughlin and Peppard [9] integrated backsourcing into an end-to-end sourcing model, which means that backsourcing is one of several alternatives of sourcing options. Finally, Beardsell [38] tried to determine whether backsourcing improves the firm's innovative capability by integrating a broad range of theories.

Many empirical interpretivist research papers were identified, which were mostly based on real case studies. Butler et al. [17] conducted six semi-structured interviews in a company that recently backsourced its whole IT department to identify parallels between backsourcing and outsourcing. A similar approach was taken by several authors ([12], [33], [39], [40]), who examined antecedents for IS backsourcing, not only based on interviews but also by analysing external media publications. This method was extended by [41]-[44], in which internal company data, such as presentations and e-mails, were considered in the analysis of determinants that have led to the failure of ISO arrangements.

Several empirical positivist research papers were identified [10], [28], [45]. They interviewed over 250 employees from various companies in field studies on the success and failure factors for ITO and identified reasons why companies backsource.

Bhagwatwar et al. [46] used an empirical descriptive approach to analyse two case studies and developed bestpractices for the success of an IS backsourcing arrangement in terms of knowledge re-integration based on their observations.

\section{Why-Stage: Backsourcing drivers}

Comparing the foci of the relevant IS backsourcing literature in this paper with those of selected papers in IS offshoring literature reviews ([1], [4], [23]), striking differences are observed. While the IT offshoring literature focusses on multiple dimensions, such as distance (onshore, nearshore, offshore), function (infrastructure, application, etc.), degree (selective, total), perspective (vendor, customer, consultant) and the stages of why, how, what and which to offshore, the IS backsourcing literature is very limited in its research perspectives. This underlines the weak pervasion of the subject matter from a research point of view.

Regarding the analysed papers, multiple types of classifications are proposed. Veltri [47] classified backsourcing drivers into costs, uncertainty and risk, goal conflict and opportunism. Wong [44] categorized his findings into strategic factors, power and politics, outsourcing expectation gaps and changes in vendor organization. A very general classification was made by Wong in 2008 [40], who categorized his findings into (1) outsourcing expectation gaps, (2) internal organizational changes and (3) external environmental changes. Driven by the content analysis of the selected publications, the categorization and sub-categorization by [40] are most suitable due to the broad variety of the obtained results.
In the following, expectation gaps are stated, followed by internal organizational changes and external environmental changes. A comparison of the results with (a) the results to the ISO and (b) manufacturing backshoring literature is performed afterwards.

(1) Backsourcing drivers through expectation gaps: The most commonly mentioned factor for moving IS services back among the selected research papers is unsatisfying service quality (mentioned in eleven of the papers). In particular, concrete factors are low product and service quality, poor communication, lower productivity, poor commitment of the vendor and a lack of transparency. An additional striking factor is cultural differences, which is reflected into different understandings of hierarchy, punctuality, acknowledging mistakes, and accuracy and responsibility over tasks. In addition, knowledge mismatch, which describes a lack of business and technology knowledge, and process comprehension and experience might lead to inefficiencies in collaboration. Independent from possible mismatches through differences of any kind, opportunistic behaviour must be considered as well, since the vendor has latitude, for example, in appointing key personnel to specific positions, which he might use to further his interests.

Furthermore, cost aspects are found to be of higher relevance, specifically unrealized cost savings through agency costs, transaction costs, hiring and retaining costs, lost performance and uncertainty costs. Through these categories, it becomes clear that cost and service quality are both highly considered in decisions on outsourcing and backsourcing IS services [26].

Losing control over the vendor's activities is also considered a central driver for backsourcing regarding possible principal-agent problems, such as inefficiencies through incorrect working directions and, especially, insecurity issues for sensitive information. From a strategic point of view, failing to achieve defined outsourcing goals is one of the most striking arguments for backsourcing. Additional drivers are uncertainties regarding objectives, performance measurements and missing measures for low performance or failure.

Lastly, an important factor for IS backsourcing is missing access to latest technologies, which refers not only to stateof-the-art soft- and hardware technologies but also to highly educated human and knowledge capital, which might lead to deficiencies in communication and cooperation and, finally, lower competitiveness.

(2) Backsourcing drivers through internal or external changes: From a company-internal organizational point of view, backsourcing can result from trivial causes, such as changes of the (top) management, changes of the role of IT in the company or general changes in the strategic direction. The last two factors go hand in hand due to the rising relevance of IT in the operations and strategies of 
companies, especially in times of digitalization of assets and products. Deduced from this, outsourcing can also occur for reasons of business model changes, organizational changes in structures (e.g., through acquisitions, mergers, or divestments) or simply through a shift or lack of top executive support.

(3) External environmental changes: Comparatively few factors were identified regarding IT backsourcing. Those factors mostly refer to changes in the vendor's strategy or organization or, from an economic perspective, uncertainties in demand and supply through economic ups and downs. A link to the technology factor can also be made, meaning that disruptive technologies might lead to new markets, which again might lead to new business models and environments that require new sourcing considerations.

(a) Comparison to ISO literature: The most frequently identified drivers for ISO are of financial and strategic nature ([2], [4], [23]). These primarily include cost reduction, wealth maximization by leveraging cost savings, access and proximity to highly skilled employees and markets, focus on core competencies and higher flexibility and technical feasibility [4]. Comparing the most striking motivations of both fields, except for the cost factor, a relatively small number of matchings occur. Considering the reviewed determinants for consideration of ISO as a sourcing option by [23], who specify factors such as advanced technology access, chance for organizational changes and higher innovativeness, similar results dominate.

However, both phenomena contribute to the success of an organization via reconsideration of the business strategy and adaption to the business environment. Additional matchings can be identified when the stated risks for ISO are compared to the drivers for IS backsourcing. Gonzalez et al. [3] addressed risks for the client from different aspects, such as economic (e.g., unemployment rates, poor infrastructure), local (e.g., differences in culture, mentality, language and knowledge transfer or legal problems) and managerial risks (e.g., low quality, additional effort, hidden costs). A striking matching regarding the results of the review is the risk of impacting (internal and external) customer relationships, which is rarely stated in the ISO literature. In their analysis, Butler et al. [17] stated that backsourcing cannot be viewed as "outsourcing in reverse", which can be confirmed in this part of the analysis.

(b) Comparison to manufacturing backshoring literature: For this comparison, two existing systematic literature reviews were used ([15], [48]), which resulted in 22 and 20 selected publications for reshoring manufacturing. Although those reviews are similar in their analysed literature and period, different methods of categorizing the drivers for reshoring manufacturing were used.

Stentoft et al. [15] synthesized and summarized their findings from the reshoring-company perspective. The following aspects were considered: cost, quality, time and flexibility, access to skills and knowledge, risks, market and other factors (e.g., incentives from governments and change of a company's strategy).

On the other side, Wiesmann et al. [48] considered an economic perspective by selecting the following driver categories: global competitive dynamics, host and home country, supply chain and firm specifics.

However, the disparity between the manufacturing reviews makes a direct comparison with the findings of our analysis difficult. Therefore, a differentiated comparison appears appropriate. On an enterprise level, the major difference between the IS service and manufacturing business seems to be the subject matter of the backsourcing arrangement: intangible vs. tangible assets, whereas in IS backsourcing, the aspects of cost and quality are considered factors that influence the collaboration between client and vendor; those factors refer more to asset and logistical costs and product quality on the manufacturing-side. Linked to the relevance of collaboration in IS, related factors, such as cultural differences and communication as well as project management, are of high importance. In terms of control, only a few factors are specified in the manufacturing literature. One reason might be the deeper integration of IS services in the company, since IS services are being used by employees abroad whereas manufacturing functions as its own entity for the most part. This stresses the relevance of IS in terms of operations and strategy (see [2]). This goes hand in hand with the high relevance of designing well-conceived contracts for facing all types of contingencies. Lastly, the IS backsourcing literature concentrates on the company layer and considers changes in strategy, management and structure as possible drivers.

In contrast, the characteristic of tangibility influences most of the arguments that are stated in the review of [15], such as production and delivery reliability, supply chain risks and the value of "Made in X"-brandings. These points emphasize that operational artefacts, especially employees, products and the production process, are of interest in the analysis of manufacturing backshoring factors. A variety of parallels and similarities can be detected. As an example, delivery reliability can be found in IS services as well in terms of system and service availability. Both fields face unplanned efforts in terms of transaction costs, miscalculations and high employee turnover rates. In addition, the access to state-ofthe-art technologies, the lack of trust and commitment and the risk of theft of intellectual property are factors that are considered as drivers for backsourcing in both IS and manufacturing.

From an economic point of view, Wiesmann et al. [48] conducted a more differentiated review than we did in our analysis by including the categories that are mentioned above. While our paper identifies backsourcing drivers that come from external sources, Wiesmann et al. [48] amplified the influence of political, economic and structural 
circumstances, specifying, for example, changes in the international and national economy, political risks, access to qualified personnel, the increasing degree of automation and international differences between productivity rates and work morale among staff. Due to their business character, these arguments can also be considered for the IS field. Competition for resources, sustainability and environmental aspects and difficulties in estimating supply and demand volumes appear to fit into the manufacturing area at first glance but touch the IS area indirectly as well (see [28], [47]).

\section{How-Stage: Re-transition process}

Comparing our findings in the IS backsourcing literature with those in the ISO literature, the infancy of IS backsourcing becomes visible only in the "how"-stage. Whereas backsourcing results in three publications (two in IS backsourcing), Dibbern et al. [2] identified 36 papers, Wiener et al. [4] considered six papers and Strasser and Westner [23] 13 papers. One reason for this difference is the maturity of ISO research. Furthermore, the limitations, which were mentioned at the beginning of this section, have to be considered, since factors such as supplier selection play an important role in the "how"-stage and might lead to the higher number of findings. Research in the "how"-stage, if narrowed down to IS backshoring literature, is comprised of four areas:

(1) transfer and management of knowledge,

(2) project management needs and challenges,

(3) the relevance of relationship management and

(4) hiring or re-hiring strategies.

(1) Transfer and management of knowledge: As IS services are more integrated into a company's infrastructure than isolated manufacturing activities, a delimitation is difficult to make ([2]). Thus, the transfer of knowledge in an IS backsourcing arrangement must be structured and accurate, due to multiple barriers, such as business requirements, geography or distance, limitations of information and communication technologies, language and problems with sharing beliefs and cultural norms ([46]). Adapting and modifying the approach in Strasser and Westner's [23] systematic literature review on ISO, this section can be divided into knowledge transfer factors and knowledge processes and roles.

Knowledge transfer factors: Most IS backsourcing and a wide range of ISO studies examine the knowledge transfer process between the client and the vendor and identify central factors that influence this process positively or negatively. As an example, in reviewing two case studies of IS backsourcing, Bhagwatwar et al. [46] argued that high transparency and the willingness to cooperate lead to positive impacts on the transfer, while neglecting the communication and the integration of the employees into the transition process lead to negative impacts. The scope of knowledge, in terms of product specifications and processes, and an environment of clear instructions play a crucial role in transferring concrete knowledge from one entity to another. Indirect influencers are formal factors, such as the level of knowledge on each side, organizational characteristics, and additional efforts for privacy preservation of company-internal data.

Knowledge processes and roles: The knowledge transfer process can be divided into different types and can therefore be explained in different process models (see [49]-[51]). It becomes clear that various types of knowledge exist; hence, different transfer methods should be applied. A prior step to the transfer is to enable the process by sensitizing affected employees on the client and vendor sides to prepare the cooperation and communication on an organizational level. Wang et al. [52] developed a process of boundary formation and spanning activities and defined the role of a boundary spanner, who navigates and negotiates existing boundaries. A second role, namely, the bridge system engineer, is defined. This role is to help minimize all types of issues regarding knowledge gaps and make the client staff aware of cultural differences between the client and the vendor (see [53], [54]).

In their literature review, Strasser and Westner [23] extended Wiener et al.'s [4] findings by identifying additional organizational practices that influence the knowledge transfer. In particular, the relevance of intermediaries and learning activities for successful knowledge transfer was determined. Comparing these findings with the existing IS backsourcing literature, most of the factors that are specified in the ITO literature are also identified but only briefly analysed.

(2) Project management challenges: Adapting and modifying Wiener et al.'s [4] results, the project management challenges for ISO can be divided into three categories: cultural differences, distances and psychological contract. Referring to the definition and characteristics of IS backsourcing, these categories can be applied in this research area as well. In the lessons that they learned from two case studies, Bhagwatwar et al. [46] emphasize the relevance of a guided re-integration process, backed by a backsourcing project team and plan. This team ideally consists of not only executives, managers and technical staff but also the mentioned bridge system engineers. The most obvious tasks of the team are to relay decisions of the vendor to all relevant parties, pay attention to existing and defined security policies and perform the business continuity planning [46]. In addition, it is an unobvious but crucial challenge to lay the groundwork for working and collaborating by defining milestones and responsibilities and overseeing deadlines and costs [4]. On an unconscious level, the project team is responsible for handling upcoming challenges in terms of providing platforms and methods for overcoming any mentality, language or communication barriers that might 
hamper the collaboration between the client and the vendor. Coordinating cultural groups over a geographical distance in different time zones while integrating all relevant stakeholders increases the difficulty of the task of project management in IS backsourcing.

(3) Relationship management: As knowledge transfer can be considered the main task and project management the main tool in the "how"-stage, effective relationship management involves an enabler and a facilitator for both aspects. According to [23], relationship management can be divided into relationship management factors, relationship management practices and strategies and client and supplier middle-management capabilities and roles.

Relationship management factors: Since a relationship exists between the client and the vendor, the similarity of factors between IS backsourcing and ISO seems obvious. Primarily, the interests of both client and vendor must be considered since different and possibly hidden motivations drive the engagement on either side [55]. On a more operational and interpersonal level, various aspects have an impact on the relationship management. While trust and the motivation for collaboration lead to a successful relation [56], missing commitment of senior management and weak employee identification influence the relationship negatively [46]. In addition, the various aspects of distance play a role in managing relationships, parallel to the challenges in project management. Since any type of backsourcing has the characteristic of finality, short-term activities seem appropriate, whereas ISO also focusses on establishing longterm strategic partnerships.

Relationship management practices and strategies: Since two organizationally and culturally different groups are in contact, specific practices and strategies appear to be necessary for a collaboration. Abbott and Jones [57] developed a framework for obtaining a better understanding of complex cross-cultural practices and processes. Based on their interviews, Mehta and Mehta [58] emphasized the need for investments in the vendor relationship to minimize the client's risk of relationship breakdown. Such investments may be face-to-face contacts or interactions and the motivation of both the vendor's and the client's employees [59]. In case of a deterioration of the relationship, for example, due a lack of team identity or blockages of communication, Mathew [60], Zimmermann [61] and Butler et al. [17] suggested contingency plans and risk mitigation strategies, such as accelerating the transition.

Client and supplier middle management capabilities and roles: Surprisingly, scant research has been published on middle managers, who execute the outsourcing on an operational level and report to the top management [2]. Willcocks and Griffiths [62] identified the capabilities and roles of middle management for both client and vendor that ensure the effectiveness of an outsourcing arrangement. To clarify the difference from the project management approach that was mentioned earlier, middle managers are domain experts, behaviour managers or governance specialists who are directly confronted with upcoming problems from the operational side. In contrast, project managers are responsible for general organizational issues regarding the project. However, overlaps in roles and tasks exist.

(4) Hiring and re-hiring strategies: Parallel to ISO and manufacturing backshoring research, information on handling human resource capacities is lacking. This phenomenon might occur in ISO, since hiring new staff is an issue of the vendor. Bhagwatwar et al. [46] stressed the relevance of having a strategy for re-transferring existing employees and hiring new employees. Backsourcing without the needed manpower is impossible, which makes it necessary to consider the availability and the need to transfer or hire staff in advance. This need is emphasized by the fact that running in-house IT functions requires people with expertise. The hiring and training of highly skilled staff and service quality assurance are time and cost issues that also must be considered in the backsourcing decision [17].

\section{Comparison to ISO and manufacturing literature:} While [2] focused more on conceptualizing and building a relationship between client and vendor, Wiener et al.'s [4] review examined the challenges of offshore relationships, including risk mitigation techniques and success factors. Strasser and Westner [23] extended these findings by specifying a range of factors that emphasize the relevance of communication and commitment of all stakeholders. In addition, they identified additional research fields regarding the role and capabilities of middle management, crosscultural and organizational learning processes and offshoring attitudes and resulting behaviours that influence relationship management of offshoring initiatives. In their study, Butler et al. [17] stressed the importance of relationship management in terms of investing in the relationship to enable a smooth knowledge transfer and avoid a relationship breakdown during the transition.

\section{DISCUSSION AND CONCLUSIONS}

This literature review presents a consolidated view of the current IS backsourcing field of study and is the first of its kind. Twenty publications critically reflect the state of research of the period between 2003 and 2016. In this article, the current state of the IS backsourcing research stream was reviewed and analysed. By partially referring to the analytical framework of [4], the perspectives of research focus and research approach were adapted. With the help of this modified framework, a common understanding of basic terms and, thus, the basis for the analysis of prior academic IS backsourcing literature was enabled. According to an analysis of the findings, the chosen framework appears to be appropriate and encourages further research in the field along the framework perspectives. 


\section{A. Current State of Research}

With its first mention in the 2000s, IS backsourcing became a field of interest in the upcoming years. Most of the papers that address the IS backsourcing phenomenon were published between 2003 and 2010, whereas only a few publications that investigated failed outsourcing arrangements appeared from 2014 to 2016 . According to the main path analysis by [1], who analysed ISO research from 1992 to 2013, IS backsourcing is only mentioned as an alternative among IS sourcing possibilities.

In total, 20 papers were identified in our literature analysis, which were published between 2003 and 2016 and consisted of eleven conference papers from nine conferences and nine journal papers in nine journals (see Table 2 in the Appendix). With the literature review at hand, one overarching finding becomes immediately apparent. Backsourcing research is in a stage of infancy. This finding is based solely on the number of publications and the foci of the papers compared to the ISO research field; such as in [23], in which the authors were able to identify and analyse 95 articles that were published from 2009 to 2013 for their literature review on ISO. However, with other reviews emerging (e.g., see [63]) the topic of backsourcing seems to gain momentum.

\section{B. Research Focus}

The findings demonstrate that the focus of research is the decision process, especially the drivers for enterprises to backsource their IT services (16 papers). Most of those findings address the concrete IS backsourcing subject, whereas three articles instead investigate failures of outsourcing arrangements. Thus, currently, it seems to be the most mature branch of the IS backsourcing research stream. One reason for this domination might be related to how backsourcing is viewed. Initially viewed as a solution for poor service quality and unmet expectations, backsourcing has become a strategy for change and innovation over time. In analysing the first large wave of publications on ISO, Dibbern et al. [2] encountered a similar domination.

Unlike the literature reviews on ISO, few articles focus on the "how" question, which refers to the implementation of the IT services back to the home country of the company. In drawing parallels to other research fields, influencing factors could be found indirectly and partially matched to findings in the IS backsourcing field due to the similarity of various characteristics of transition processes. Accordingly, future research should further address the implementation aspect of the re-implementation stage of IS backsourcing.

According to the search results, a stronger focus should be laid on the implementation phase, to determine what influences the transition phase and what outcomes can be expected. Distinctions between IS backsourcing and backshoring could be examined to a similar extent as in ISO research. Switching the point of view may lead to additional insights. Integrating various stakeholder perspectives might enhance the robustness of IS backsourcing research results. Furthermore, research on hiring and re-hiring strategies should be conducted, both in IS backsourcing and ISO. Having this in mind, more research should be conducted on comparing the phenomena of backsourcing and outsourcing.

\section{Research Approach}

Most of the reviewed publications make use of empirical research methods (13 papers), which are dominated by interpretive (nine papers) and followed by positivist research (three papers). Interpretive research is conducted across both stages whereas positivist research only considers the "why"stage. Descriptive research is used only once. Among the empirical research methods, case studies are by far the most popular. Non-empirical research was conducted in seven articles, in each case in a conceptual manner. The allocation of the empirical papers corresponds to the findings of [4] and [23], except that the share of the conceptual papers is higher.

Considering the current predominance from an interpretive epistemological view, a more balanced application of interpretive and positivist methods seems appropriate. As the research field is emergent, descriptive studies should be conducted as well. The obvious dominance of case study research should be complemented by a wider use of other methods (e.g., field study research and action research) and the design of research approaches.

\section{D.Future Research}

Apart from the small number of search results for IS backsourcing, future research should primarily consider all perspectives along the multi-perspective framework, following [2], [4]. Thus, one goal might be a higher pervasion of IS backsourcing research to be able to subdivide the two main stages that are specified in this paper into sub-stages according to the five-stage model. To complete the analytical framework of [4], a third perspective should be considered in future, namely, reference theory. Matching various approaches and their conclusions with existing theories might lead to additional insights and research questions and could function as an extension of the review at hand. Future research should be aimed at building a fundamental understanding of the phenomenon of backsourcing by varying the points of view, investigating various cases and scenarios and applying various research approaches to verify and extend previous findings.

\section{REFERENCES}

[1] H. Liang, J.-J. Wang, Y. Xue, and X. Cui, "IT outsourcing research from 1992 to 2013," Inf. Manage., vol. 53, no. 2, pp. 227-251, 2016. doi: 10.1016/j.im.2015.10.001.

[2] J. Dibbern, T. Goles, R. Hirschheim, and B. Jayatilaka, "Information systems outsourcing," ACM SIGMIS Database, vol. 35, no. 4, pp. 6-102, 2004. doi: 10.1145/1035233.1035236.

[3] R. Gonzalez, J. Gasco, and J. Llopis, "Information Systems Offshore Outsourcing,” Inf. Syst. Manag., vol. 27, no. 4, pp. 340-355, 2010. doi: 10.1080/10580530903455205.

[4] M. Wiener, B. Vogel, and M. Amberg, "Information Systems Offshoring - A Literature Review and Analysis," Commun. Assoc. 
Inf. Syst., vol. 27, no. 1, pp. 455-492, 2010.

[5] R. Aron and J. V. Singh, "Getting Offshoring Right," Harv. Bus. Rev., vol. 83, no. 12, pp. 135-143, 2005.

[6] H. T. Barney, G. C. Low, and A. Aurum, "The Morning After: What Happens When Outsourcing Relationships End?," in Information Systems Development, G. A. Papadopoulos, W. Wojtkowski, G. Wojtkowski, S. Wrycza, and J. Zupancic, Eds. Boston, MA: Springer, 2009, pp. 637-644. doi: 10.1007/b137171_66.

[7] C. Ebert, "Optimizing Supplier Management in Global Software Engineering," in Proceedings of ICGSE 2007, 2007.

[8] T. Kern and L. Willcocks, The relationship advantage: information technologies, sourcing, and management. Oxford, New York: Oxford University Press, 2001

[9] D. Mclaughlin and J. Peppard, "IT backsourcing: from 'make or buy' to "bringing it back in-house," in Proceedings of ECIS 2006.

[10] D. Whitten and D. Leidner, "Bringing IT Back: An Analysis of the Decision to Backsource or Switch Vendors," Decis. Sci., vol. 37, no. 4, pp. 605-621, 2006. doi: 10.1111/j.1540-5414.2006.00140.x.

[11] R. Hirschheim and M. Lacity, "The myths and realities of information technology insourcing," Commun. $A C M$, vol. 43 , no. 2 , pp. 99-107, 2000. doi: 10.1145/328236.328112.

[12] S. F. Wong, "Understanding IT Backsourcing Decision," in Proceedings of PACIS 2008, 2008.

[13] J. vom Brocke, A. Simons, B. Niehaves, K. Reimer, R. Plattfaut, and A. Cleven, "RECONSTRUCTING THE GIANT," in Proceedings ECIS 2009, 2009.

[14] H. M. Cooper, L. V. Hedges, and J. C. Valentine, Eds., The handbook of research synthesis and meta-analysis, 2nd ed. New York: Russell Sage Foundation, 2009.

[15] J. Stentoft, J. Olhager, J. Heikkilä, and L. Thoms, "Manufacturing backshoring: a systematic literature review," Oper. Manag. Res., vol. 9, no. 3-4, pp. 53-61, 2016. doi: 10.1007/s12063-016-0111-2.

[16] J. Webster and R. T. Watson, "Analyzing the Past to Prepare for the Future," MIS Q., vol. 26, no. 2, pp. 13-23, 2002.

[17] N. Butler, F. Slack, and J. Walton, "IS/IT Backsourcing - A Case of Outsourcing in Reverse?," in Proceedings of HICSS 2011, 2011.

[18] L. Fratocchi, C. Di Mauro, P. Barbieri, G. Nassimbeni, and A. Zanoni, "When manufacturing moves back," J. Purch. Supply Manag., vol. 20, no. 1, pp. 54-59, 2014. doi: 10.1016/j.pursup.2014.01.004

[19] M. Amberg and M. Wiener, IT-Offshoring: Management internationaler IT-Outsourcing-Projekte. Heidelberg: PhysicaVerlag, 2006.

[20] J. V. Gray, K. Skowronski, G. Esenduran, and M. Johnny Rungtusanatham, "The Reshoring Phenomenon: What Supply Chain Academics Ought to know and Should Do," J. Supply Chain Manag., vol. 49, no. 2, pp. 27-33, 2013. doi: 10.1111/jscm.12012.

[21] M. Westner and S. Strahringer, "Current state of IS offshoring research. A descriptive meta-analysis," in Proceedings of the First Workshop on Offshoring of Software Development - Methods and Tools for Risk Management, 2008.

[22] E. Carmel and R. Agarwal, "Tactical approaches for alleviating distance in global software development," IEEE Softw., vol. 18, no. 2, pp. 22-29, 2001. doi: 10.1109/52.914734.

[23] A. Strasser and M. Westner, "Information Systems Offshoring: Results of a Systematic Literature Review," J. Inf. Technol. Manag., vol. 26, no. 2, pp. 70-142, 2015.

[24] J. Dibbern and A. Heinzl, "Outsourcing of Information Systems Functions in Small and Medium Sized Enterprises: A Test of a MultiTheoretical Model," Bus. Inf. Syst. Eng., vol. 1, no. 1, pp. 101-110, 2009. doi: 10.1007/s12599-008-0008-1.

[25] R. Hirschheim, C. Loebbecke, M. Newman, and J. Valor, "Offshoring and its Implications for the Information Systems Discipline," in Proceedings of ICIS 2005, 2005.

[26] R. Hirschheim, G. Beena, and S. F. Wong, "Information technology outsourcing: The move towards offshoring," Indian J. Econ. Bus., vol. 3.2004, pp. 103-123, 2004.

[27] J. Akoka and I. Wattiau, "Developing a Framework for Analyzing IS/IT Backsourcing," in Proceedings of the 11th International Conference of the Association Information and Management (AIM 2006), 2006
[28] N. F. Veltri, C. S. Saunders, and C. B. Kavan, "Information Systems Backsourcing: Correcting Problems and Responding to Opportunities," Calif. Manage. Rev., vol. 51, no. 1, pp. 50-76, 2008 doi: $10.2307 / 41166468$.

[29] B. Martens and F. Teuteberg, "Bewertung von BacksourcingEntscheidungen im Umfeld des Cloud Computing," in Proceedings MKWI 2010, 2010.

[30] S. Kinkel and S. Maloca, "Drivers and antecedents of manufacturing offshoring and backshoring," J. Purch. Supply Manag., vol. 15, no. 3, pp. 154-165, 2009. doi: 10.1016/j.pursup.2009.05.007.

[31] R. Holz, An investigation into offshoring and backshoring in the German automotive industry. Doctoral Thesis, Swansea University, 2011.

[32] S. Kinkel, "Trends in production relocation and backshoring activities," Int. J. Oper. Prod. Manag., vol. 32, no. 6, pp. 696-720, 2012. doi: 10.1108/01443571211230934.

[33] J. Kotlarsky and L. Bognar, "Understanding the process of backsourcing," J. Inf. Technol. Teach. Cases, vol. 2, no. 2, pp. 7986, 2012. doi: 10.1057/jittc.2012.7.

[34] G. R. G. Benito, B. Petersen, and L. S. Welch, "Mode Combinations and International Operations," Manag. Int. Rev., vol. 51, no. 6, pp. 803-820, 2011. doi: 10.1007/s11575-011-0101-4.

[35] J. L. Calof and P. W. Beamish, "Adapting to foreign markets: Explaining internationalization," Int. Bus. Rev., vol. 4, no. 2, pp. 115-131, 1995. doi: 10.1016/0969-5931(95)00001-G.

[36] R. V. Ţurcan, M. M. Mäkelä, O. J. Sørensen, and M. Rönkkö, "Mitigating theoretical and coverage biases in the design of theorybuilding research," Int. Entrep. Manag. J., vol. 6, no. 4, pp. 399-417, 2010. doi: 10.1007/s11365-009-0122-7.

[37] L. M. Ellram, "Offshoring, Reshoring and the Manufacturing Location Decision," J. Supply Chain Manag., vol. 49, no. 2, pp. 3-5, 2013. doi: $10.1111 / \mathrm{jscm} .12023$.

[38] J. Beardsell, "IT Backsourcing: Is it the Solution to Innovation?," SMC Working Papers Series, No. 02/2010, Swiss Management Center, 2010

[39] B. B. Nujen, L. L. Halse, and H. Solli-Sæther, "Backsourcing and Knowledge Re-integration: A Case Study," in Advances in Production Management Systems, S. Umeda, M. Nakano, H. Mizuyama, H. Hibino, D. Kiritsis, and G. von Cieminski, Eds. Cham: Springer, 2015, pp. 191-198. doi: 10.1007/978-3-319-22759-7_22.

[40] S. F. Wong, "Drivers of IT Backsourcing Decision," Commun. IBIMA, vol. 2, no. 14, pp. 102-108, 2008.

[41] R. Chandrasekaran, A. Tayeh, and V. Nagoore, "Understanding Information System Outsourcing Failure: Lessons from a Case Study," in Proceedings of AMCIS 2007, 2007.

[42] N. B. Moe, D. Šmite, G. K. Hanssen, and H. Barney, "From offshore outsourcing to insourcing and partnerships," Empir. Softw. Eng., vol. 19, no. 5, pp. 1225-1258, 2014. doi: 10.1007/s10664-013-9272-x.

[43] T. Philip, G. Schwabe, and K. Ewusi-Mensah, "Critical Issues of Offshore Software Development Project Failures," in Proceedings of ICIS 2009, 2009.

[44] S. F. Wong, "Bringing IT Back Home: Developing Capacity for Change," in Proceedings of ICIS 2006, 2006.

[45] G. P. A. J. Delen, R. J. Peters, C. Verhoef, and S. F. M. van Vlijmen, "Lessons from Dutch IT-outsourcing success and failure," Sci. Comput. Program., vol. 130, pp. 37-68, 2016. doi: 10.1016/j.scico.2016.04.001.

[46] A. Bhagwatwar, R. Hackney, and K. C. Desouza, "Considerations for Information Systems 'Backsourcing'," Inf. Syst. Manag., vol. 28, no. 2, pp. 165-173, 2011. doi: 10.1080/10580530.2011.562132.

[47] N. F. Veltri, "Antecedents of IS Backsourcing," in Proceedings of AMCIS 2003, 2003

[48] B. Wiesmann, J. R. Snoei, P. Hilletofth, and D. Eriksson, "Drivers and barriers to reshoring," Eur. Bus. Rev., vol. 29, no. 1, pp. 15-42, 2017. doi: 10.1108/EBR-03-2016-0050.

[49] J. Chen and R. J. McQueen, "Knowledge transfer processes for different experience levels of knowledge recipients at an offshore technical support center," Inf. Technol. People, vol. 23, no. 1, pp. 54-79, 2010. doi: 10.1108/09593841011022546.

[50] Y. Feng, H. Ye, and S. L. Pan, "Delivering Knowledge across Boundaries," in Proceedings of PACIS 2010, 2010. 
[51] K. Schott, "Vendor-Vendor Knowledge Transfer In Global ISD Outsourcing Projects," in Proceedings of PACIS 2011, 2011.

[52] Z. Wang, E. J. Chen, S.-L. Pan, and Y. Wu, "Bridging Boundaries in Offshore Outsourcing Organizations," in Proceedings HICSS 2011, 2011.

[53] N. T. Huong, U. Katsuhiro, and D. H. Chi, "Knowledge Transfer in Offshore Outsourcing," J. Glob. Inf. Manag., vol. 19, no. 2, pp. 27-44, 2011. doi: 10.4018/jgim.2011040102.

[54] V. Mahnke, J. Wareham, and N. Bjorn-Andersen, "Offshore middlemen: transnational intermediation in technology sourcing," $J$. Inf. Technol., vol. 23, no. 1, pp. 18-30, 2008. doi: 10.1057/palgrave.jit.2000124.

[55] S. S. Bharadwaj, K. B. C. Saxena, and M. D. Halemane, "Building a successful relationship in business process outsourcing," Eur. J. Inf. Syst., vol. 19, no. 2, pp. 168-180, 2010. doi: 10.1057/ejis.2010.8.

[56] H. Kefi, A. Mlaiki, and R. L. Peterson, "IT Offshoring: Trust Views from Client and Vendor Perspectives," Int. J. Inf. Technol. Proj. Manag., vol. 2, no. 2, pp. 14-31, 2011. doi: 10.4018/IJTPM.201104012011040102.

[57] P. Y. Abbott and M. R. Jones, "Everywhere and nowhere: nearshore software development in the context of globalisation," Eur. J. Inf. Syst., vol. 21, no. 5, pp. 529-551, 2012. doi: 10.1057/ejis.2012.7.

[58] N. Mehta and A. Metha, "Reducing Client Risks from Offshore IT Vendors' HR Challenges," MIS Q. Exec., vol. 8, no. 4, pp. 191-201, 2009.

[59] A. Boden, B. Nett, and V. Wulf, "Operational and Strategic Learning in Global Software Development," IEEE Softw., vol. 27, no. 6, pp. 58-65, 2010. doi: 10.1109/MS.2009.113.
[60] S. K. Mathew, "Mitigation of risks due to service provider behavior in offshore software development: A relationship approach," Strateg Outsourcing Int. J., vol. 4, no. 2, pp. 179-200, 2011. doi: $10.1108 / 17538291111148008$.

[61] A. Zimmermann, "Offshoring attitudes, relational behaviours, and departmental culture," in Proceedings of ECIS 2011, 2011.

[62] L. Willcocks and C. Griffiths, "The Crucial Role of Middle Management in Outsourcing," MIS Q. Exec., vol. 9, no. 3, pp. 177-193, 2010.

[63] von Bary, Benedikt and Westner, Markus, "Information Systems Backsourcing: A Literature Review," J. Inf. Technol. Manag., vol. 29, no. 1, pp. 62-78, 2018.

[64] L. C. e Silva, A. P. H. de Gusmao, M. M. Silva, T. Poleto, and A. P. C. S. Costa, "Analysis of IT Outsourcing Services Failures Based on an Existing Risk Model," in Proceedings of the 2015 IEEE International Conference on Systems, Man, and Cybernetics (SMC 2015), 2015.

[65] H. Solli-Sæther and P. Gottschalk, "Stages-of-Growth in Outsourcing, Offshoring and Backsourcing: Back to the Future?," $J$. Comput. Inf. Syst., vol. 55, no. 2, pp. 88-94, 2015. doi: 10.1080/08874417.2015.11645760.

TABLE II.

OVERVIEW OF THE RESEARCH PAPERS FROM THE LITERATURE REVIEW

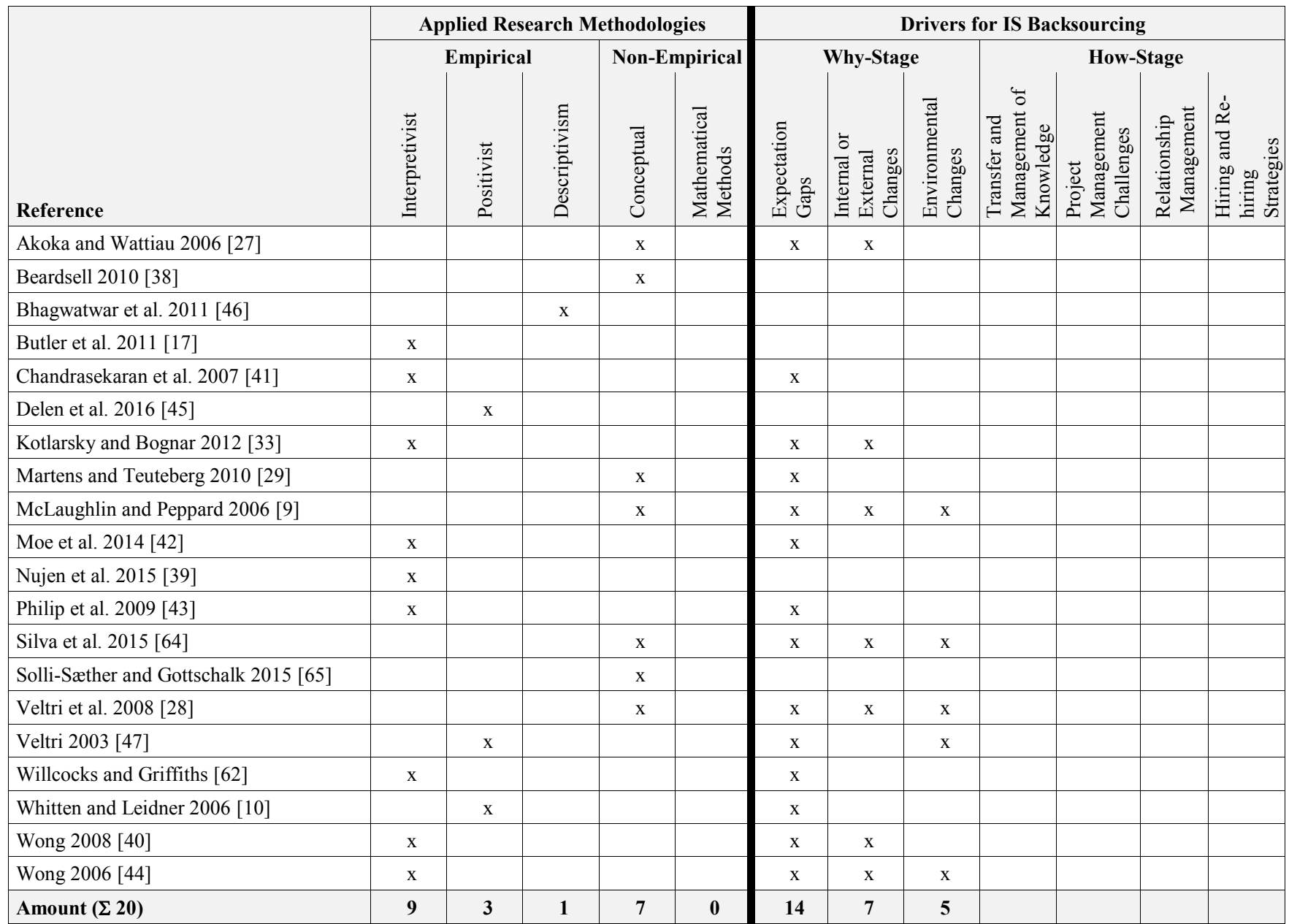

